\title{
Sobre chuteiras e coturnos: Futebol como instrumento de soft power de regimes autoritários na Argentina, Brasil e Chile
}

Ian Rebouças Batista:

Laryssa R. Vidal A. de Souza: ian.reboucas@ufpe.br

Universidade Federal de Pernambuco (Brasil)

Centro Universitário Estácio do Recife

Recibido: $24 / 03 / 2020$

Aceptado: $27 / 10 / 2021$

Resumo: Sendo o esporte um dos elementos culturais mais importantes do século XX, e o futebol em particular um dos instrumentos que favorecem a identidade nacional dos países do Cone Sul, o presente trabalho propõe analisar se o uso propagandístico que os governos militares das décadas de 60 e 70 faziam do futebol refletiu em ganhos desoft powerpara esses Estados. Analisamos os regimes da Argentina, Brasil e Chile e a relação desses governos com as seleções nacionais de futebol em momentos cruciais de tentativa de associação, analisando as experiências e o conceito. Concluímos que somente para o Brasil o futebol possibilitou ganhos de legitimidade e influência internacional.

Palavras-chave: Estados Burocráticos-Autoritários. Futebol. Soft Power. Política Externa. Propaganda.

* Cómo citar este artículo: Rebouças Batista, I. y Vidal A. de Souza, L. (2021). Sobre chuteiras e coturnos: Futebol como instrumento de soft power de regimes autoritários na Argentina, Brasil e Chile. Relaciones Internacionales, 30 (61), 136. https://doi.org/10.24215/23142766e136 


\section{De botines y botas: el fútbol como instrumento de soft po- wer de regímenes autoritarios en Argentina, Brasil y Chile ${ }^{1}$}

\section{lan Rebouças Batista², Laryssa R. Vidal A. de Souza3}

Resumen: Dado que el deporte es uno de los elementos culturales más importantes del siglo XX y el fútbol, en particular, uno de los instrumentos que favorecen la identidad nacional de los países del Cono Sur, el presente trabajo propone analizar el uso propagandístico que los gobiernos militares de los 60 y 70 hicieron, en los que el fútbol se refleja en soft power para estos Estados. Analizamos los regímenes en Argentina, Brasil y Chile, y la relación de estos gobiernos con los equipos nacionales de fútbol en momentos cruciales de intento de asociación, a partir del estudio de las experiencias y el concepto. Concluimos que solo para Brasil el fútbol permitió ganancias en legitimidad y influencia internacional.

Palabras clave: Estados BurocráticosAutoritarios. Fútbol. Soft Power. Política Exterior. Propaganda.

1 Este trabalho é fruto do Trabalho de Conclusão de Curso de Laryssa Vidal, orientado por lan Rebouças Batista. Os autores agradecem aos comentários realizados pelos avaliadores Deywisson Souza e Amanda Domingos na banca de defesa.

2 Pesquisador Visitante na Universidade de Notre Dame. Doutorando em Ciência Política na Universidade Federal de Pernambuco. Mestre em Ciência Política pela Universidade Federal do Rio Grande do Sul e Bacharel em Relações Internacionais pela Universidade Federal de Sergipe.

3 Bacharel em Relações Internacionais pelo Centro UniversitárioEstácio do Recife. 


\title{
On football and military boots: Football as a soft power instrument for authoritarian regimes in Argentina, Brazil and Chile
}

Ian Rebouças Batista, Laryssa R. Vidal A. de Souza

\begin{abstract}
As sports were one of the main cultural elements during the 20thCentury and football specifically was used as an instrument to strength national identity in South America, this paper aims at analyzing the propagandistic use of football made by the military governments from the 60s and 70s, in which this sport may have turned into soft power. We analyze the governments of Argentina, Brazil and Chile and their relationship with the national football teams at specific times when associations with it were attempted, paying attention to the experiences and the concept. We conclude that only for Brazil football provided benefits in both legitimacy and international influence.
\end{abstract}

Keywords: Bureaucratic-Authoritarian State. Football. Soft Power. Foreign Policy. Propaganda. 


\section{Introducción}

Uma nova ordem social, econômica e política acometeu os países do Cone Sul logo após as rupturas democráticas nos anos 60 e 70. A expansão do mercado e as pressões do capital internacional, além dos interesses ideológicos no combate dos movimentos esquerdistas, promoveram na região uma modernização estrutural forçada, via golpes militares, acarretando em conflitos políticos na América Latina (Junior e Livacic, 2017).

No referido período, Argentina, Brasil e Chile tiveram governos marcados por alto grau de autoritarismo, levando as populações a sofrerem diversas implicações violentas por parte dos ditadores. Na tentativa de construir uma legitimidade no cenário nacional, em vista todo o clima hostil presente nos países, é possível identificar que os militares adotaram a propaganda nacionalista via o futebol como uma das formas de mascarar os problemas internos acometidos nesse período (Brum, 2017; Dias, 2015).

Sabendo que o Soft Power é o poder de atrair e cooptar um país, a fim de garantir um resultado desejado (Nye, 2004), a utilização dos elementos culturais como música, esportes e as artes pode ser considerado um instrumento prático inclusivo que promove e favorece relações diplomáticas entres os Estados-Nação (Amazarray, 2011). É preciso salientar, contudo, que esse conceito (Soft Power) foi desenvolvido na disciplina das Relações Internacionais (RI) pelo cientista político Joseph Nye no final da década de 1980, em um mundo mais globalizado e interdependente. Entretanto, sabe-se do papel fundamental que a propaganda obtém nos planos dos regimes autoritários (Arendt, 1951). Dessa maneira, a hipótese do presente trabalho é a de que o uso que governos autoritários sul-americanos faziam do futebol e suas seleções nacionais pode ser caracterizado como Soft Power tal qual é compreendido na literatura recente das RI.

Essa hipótese se constrói a partir do entendimento do futebol como um dos fenômenos culturais mais importantes do século XX (Houlihan, 1994, p. 52). O sociólogo Richard Giulianotti (2010, p. 42), por exemplo, aponta que: "o esporte, e principalmente o futebol, é composto por elementos importantes como: linguagem, aspectos geográficos, classes e culturais". De modo que o esporte se mostra além de um componente recreativo e sim como possível aplicação para atos políticos por parte de governos e Estados.

Sendo assim, o esporte pode ser um dos instrumentos utilizados pelos Estados para propagação de regimes, aumentar ou reforçar o seu papel dentro do cenário internacional (Garcia, 2015). O objetivo do presente artigo, portanto, é analisar através desse olhar crítico a capacidade de poder político que o futebol pode exercer para além de somente uma atividade lúdica e lazer, visando, dessa forma, reconhecer a importância do presente estudo para a aérea das Relações Internacionais.

Na tentativa de justificar a hipótese principal dessa pesquisa, o estudo realizará uma revisão bibliográfica para apresentar e compreender os Estados Burocráticos-Autoritários sul-americanos (O'Donnell, 1972). Através do estudo de três casos onde os governos autoritários sul-americanos tentaram vincular sua imagem às seleções nacionais de futebol, buscará se aproximar da literatura das Relações Internacionais que discute a vigência e as possibilidades de se discutir Soft Power no comportamento estatal. 
O artigo está dividido nos seguintes blocos de análise. No primeiro encaminha-se uma descrição sobre os regimes autoritários burocráticos que governavam os países do Cone Sul à época estudada. Elucidando de maneira sucinta as características de cada país com relação aos golpes militares sofridos, além de suas implicações no âmbito interno e futuras ambições e alianças no cenário internacional. A segunda seção do presente trabalho pretende mostrar ao leitor casos de repercussão internacional na perspectiva de como o futebol foi utilizado a título de aparato político dos países: Argentina (Copa do Mundo de 1978), Brasil (Copa do Mundo de 1970) e Chile (repescagem da eliminatória para a Copa do Mundo, contra a União Soviética, 1973) aprofundando o embasamento teórico sobre a importância da análise do instrumento futebol para a área de pesquisa das Relações Internacionais. A terceira parte, por fim, visa discutir a hipótese do trabalho sobre como o elemento do futebol foi, ou não, um instrumento estratégico utilizado pelos regimes autoritários sul-americanos para propagação e promoção global desses. As considerações finais encerram este trabalho.

\section{2. governos autoritários sul-americanos}

À época da disputa ideológica da Guerra Fria os países periféricos enfrentaram um período de instabilidade social e política. Particularmente, esse período ficou marcado por uma tensão por parte do governo norte-americano sobre uma possível expansão do comunismo soviético na região da América Latina devido as fragilidades identificadas nos países de Terceiro Mundo. O "perigo vermelho" era evidente e eminente para os capitalistas, principalmente logo após a Revolução Cubana (1959), da qual mesmo a URSS com uma visão mais pragmática em relação ao Terceiro Mundo tomou Cuba sob sua proteção, potencializando o risco e tensão em relação à potência hegemônica capitalista com possíveis influências socialistas dentro de sua própria região. Os Estados Unidos, na tentativa de afastarem o fantasma comunista para longe de seu continente, utilizou de vários métodos para manter um nível de influência satisfatório e salvaguardar a região em seu guarda-chuva, dentre eles destaca-se a implementação da Aliança Para o Progresso ${ }^{4}$, que visava gerar propaganda ideológica e ajuda econômica aos países da América Latina (Hobsbawn, 1995).

Nas décadas de 1960 e 1970 assistiram-se mudanças significativas nos âmbitos sociais, econômicos e políticos, logo após um período das novas aspirações redistributivas de governos esquerdistas na América Latina. Como consequência disso, os países financiados pela potência capitalista para afastar o medo comunista da América Latina foram palco de diversos golpes militares (Monteiro, 2012). Essa onda de Estados autoritários foi responsável não só por uma mudança na perspectiva política do afastamento vermelho, mas também na mudança, mesmo que de forma tardia, da visão econômica em busca da industrialização

4 Programa político criado pelo governo norte-americano no mandato do presidente John F. Kennedy que tinha como objetivos além de integrar os países da América Latina ao EUA nos aspectos culturais, sociais e econômicos - chegando a marca em apoio financeiro em 20 bilhões - também dispersar as ameaças soviéticas. 
desses países (Ricupero, 2014). Através da perspectiva tecnocrática ${ }^{5}$, é evidente o objetivo desses golpes de derrotar o setor popular das questões públicas (O’Donnell, 2013).

Esse período é entendido na América Latina como de um "Novo Autoritarismo", caracterizado "pelo controle do aparelho do Estado, a hierarquia militar e pela supremacia ideológica" (Monteiro, 2012, p. 3). Nesse sentido, os Estados Burocráticos foram comandados por indivíduos com carreiras em organizações burocráticas, como o próprio Estado, empresas privadas e, principalmente, as Forças Armadas.

A criação do conceito de Estados Burocráticos-Autoritários (EBA) na América Latina surge da análise de Guillermo O'Donnell (1936-2011) na busca por entender a continuação da onda política autoritária que já se acometia na região desde $1954^{6}$. Segundo Monteiro (2012, p. 2) o conceito dos EBA, entretanto, se expande para além do chamado "Autoritarismo Tradicional", conceito do qual entende-se como "quando um líder militar ou uma família dotada de uma milícia ocupa o governo do país", e observa como as economias mais complexas da América do Sul teriam como novidade o caráter burocrático. Isso se explicaria na clara necessidade das chamadas substituições das importações e da urgência para a industrialização dos países do Cone Sul como Brasil, Argentina e Chile, objetos de interesse deste trabalho, que em certa medida se equiparam e convergem em situações semelhantes antes e durante os regimes.

Sobre a experiência brasileira, o avanço das forças populares no Brasil, principalmente no governo do presidente João Goulart (1918-1964), e sua política de valorização trabalhista, além da sua defesa da independência brasileira nas questões voltadas as relações exteriores, causaram desagrado aos interesses do patronado brasileiro (Borges, 2012). Ainda que o Brasil pré-1964 tenha vivido seu período mais democrático até então, entre os anos de 1945-1964 (Barros, 2011), é sabido que desde a Revolução de 1930 houve no país diversas tentativas e golpes, além de deposições de presidentes eleitos, sendo dessa maneira precursores daquele que durou 26 anos de regime militar no país (1964-1990).

O golpe civil-militar sofrido pelo Estado brasileiro em 1964 daria início a uma série de novos autoritarismos na região, decorrentes de uma elite insatisfeita, após rebeliões, perda de sustentação popular e, acima de tudo, incentivos norte-americanos contra uma possível nova ameaça comunista na região. Foi o começo do Cone Sul na investida capitalista à essas possíveis reformas e avanços sociais.

No caso argentino, os militares tomaram o poder em diversas oportunidades a partir de 1930. Foram seis sucessíveis golpes entre os anos de 1930 e 1976. Passado a década infame $^{7}$ (1930-1943), mesmo após algumas modificações no cenário político, com uma

5 Perspectivas do Estado ligadas a grandes empresas e responsáveis pelas políticas econômicas ao longo da ditadura (O’Donnell, 1990).

6 Golpe de Estado sofrido pelo Paraguai através do general Alfredo Stroessner, logo após duas décadas de crises,estabilidades políticas e sociais no país.

7 Período, a partir de 1930, sofrido pela Argentina com intensa fraude eleitoral, corrupção generalizada e perseguição as oposições políticas e. Enfatizado por Candeas (2005, p. 7) como: “período de deterioração política que contrasta com a exuberância cultural". 
maior participação de novos atores sociais nas práticas políticas e o advento do peronismo, retomou-se, entre as anos de 1955 e 1966, um alto nível de instabilidade, gerando mais uma vez um novo ciclo de golpes e tentativas de restauração da democracia (Catela, 1998).

Em face de uma crise de desabastecimentos, atentados, corrupção e inflação, o clima político no país no ano de 1976 era visto como "nação em caos", de modo que o golpe aplicado pela tríade das Forças Armadas (Exército, Marinha e Aeronáutica) viria, segundo os militares, reestabelecer a ordem (Catela, 1998, p. 3-4). Tal ordem, no entanto, viria por meios de censuras e restrição aos direitos civis além da perseguição violenta aos contrários do regime. Como coloca Neto (2006), os governos argentinos se pautaram pelo uso da força no intuito de construir uma potência. O elemento ideológico à blindagem do comunismo foi presente também na política externa argentina durante o regime autoritário, visto as mudanças na abordagem da política internacional do país - à época com instituições tradicionais nas mãos dos militares incluindo, nesse sentido, o ministério das relações exteriores na tentativa de desempenhar para a Argentina um reconhecimento no cenário internacional com status de potência emergente, aliada do Ocidente Capitalista (Moneta, 1986; Portilho, Barbosa, 2016). Entretanto as investidas esbarravam na falta de informações concretas concebidas pelo Estado, em face da censura, sobre as áreas da política, social e cultural do país, o que causou tensão e conflito protagonizado pela Argentina dentro do Cone Sul, em especial com o vizinho Brasil. É importante salientar, por fim, que mesmo diante da prerrogativa de afastamento socialista a Argentina continuou sem maiores quebras nas suas relações com a URSS (Portilho, Barbosa, 2016).

O Chile, em particular, quando comparado aos outros países da América Latina é considerado um país que respeitara os alicerces da institucionalidade (Júnior, 2014), onde nos anos entre 1932 e 1973 tivera eleições presidenciais democráticas. Contudo, logo após as eleições de 1970 os conflitos de caráter político-social se aprofundaram. As reivindicações dos conservadores e do setor empresarial ocorrem mais incisivamente depois de várias paralisações e greve de setores econômicos do país que contava também com o apoio externo. Como afirma Junior (2014):

(...) a construção do que seria o estado burocrático-autoritário chileno estabeleceria vínculos que estariam ligados aos interesses da burguesia nacional gerando assim uma política monetarista ortodoxa. (p. 14)

Diante desse cenário, proliferam partidos políticos a partir da fragmentação dos grupos sociais no país, instaurando-se a instabilidade institucional e permitindo ascensão da direita no Chile (Paniago, 2016). O golpe organizado pelas Forças Armadas à Salvador Allende em 1973 foi gestado por financiamento norte-americano ${ }^{8}$ em campanhas para a deposição do governo socialista (Ávila, 2014). Impôs-se no Chile, então, um governo autoritário bastante repressivo e violento sem paralelo a qualquer outro golpe latino-americano

8 Documento divulgado pelo governo norte-americano, em 2014, mostra a relação próxima entre os EUA e o Chile no período compreendido entre 1969 e 1973 do qual ocorreram-se apoio financeiro para a oposição ao governo socialista chileno, de forma encoberta (Department Of State, 2014) . 
à época. Os governos autoritários do Cone Sul, como um todo, foram marcados por perseguições ideológicas ocasionando prisões políticas de lideranças e artistas contrários a "ordem" do regime, torturas, assassinatos e exílios no pretexto anticomunista e da Segurança Nacional por parte dos militares. Ilustrando o caráter mais nefasto do regime chileno, houve ainda o uso do Estádio Nacional do Chile como campo de concentração para prisioneiros políticos contrários ao regime (Cifuentes, 2015).

É sobre os referidos regimes e sobre os instrumentos de legitimidade desses que o presente trabalho se constitui. Para além da violência e da repressão, é possível falar em uso de Soft Power por esses regimes? Mais especificamente, é possível falar do futebol enquanto elemento propagandístico com relevância na legitimação interna, e possivelmente nos âmbitos internacionais, dos governos autoritários do Cone Sul?

\section{3. os casos}

O futebol é aqui compreendido como um elemento com função política capaz de gerar um caráter simbólico de representação de uma nação, de Estados e até de governos, sendo eles autoritários ou não (Fraga, 2011). O futebol enquanto fenômeno popular aumentou sua influência no mundo e em certa medida também possibilitou sua utilização como instrumento político de Estados, como uma demonstração de poder e, por consequência, atingindo uma condição geopolítica, desempenhando papeis fundamentais nos âmbitos interno e externo (Canettiere, 2010). É com base numa suposta capacidade de promoção política de uma nação através do futebol que nessa seção iremos investigar três casos onde as seleções nacionais de futebol dos países sul-americanos foram utilizadas como propaganda para seus regimes.

\section{a) ARgENTINA (1978) - A Copa da Argentina}

A realização de uma Copa do Mundo dentro de seu próprio território é um símbolo de prosperidade de uma nação. Isso se dá, na maior parte das vezes, pelo fato da realização de obras de adequação na infraestrutura por parte do país sede para a execução do evento internacional. No caso da Copa de 1978 na Argentina, depois do espetáculo mundial visto na Copa de 70, realizada no México, e de seu sucesso televisivo, as implicações foram ainda maiores: seu uso pode ser entendido como uma tentativa de angariar benefícios na promoção do regime militar então vigente no país (Roldán, 2007; Couto, 2010; Magalhães, 2013; Marczal, 2016).

A utilização do esporte como unidade nacionalista foi inicialmente plano de governo de Juan Domingo Péron (1973-1974), mesmo que, segundo Llonto (2005), o presidente não nutrisse tanta afeição pelo futebol. No início do século XX, era evidente a disseminação da modalidade na América do Sul como um todo e na Argentina não era diferente, principalmente através dos clubes locais e posteriormente, após a realização da primeira Copa do Mundo em 1930, ocorrida no Uruguai, a afeição da população pela seleção nacional (Frydenberg, 1999; Guterman, 2006). Foi a popularidade do esporte e o desejo de se equiparar aos vizinhos uruguaios, bicampeões mundiais, e brasileiros, que após o tricampeonato mun- 
dial em 1970 atingiram um lugar privilegiado no futebol da região e prestigio mundial (Magalhães, 2013: 70), que fez com que Perón alimentasse o desejo da realização do evento da FIFA na Argentina, feito confirmado logo após a Copa da Inglaterra em 1966 (Marczal, 2016).

Ao compasso que iria cada vez mais se institucionalizando, profissionalizando e se popularizando o futebol argentino adquiriu um maior caráter político, principalmente, após a intervenção militar no país em 1976 (Roldán, 2007). A escolha de um integrante de confiança das Forças Armadas para a presidência da Associação do Futebol Argentino (AFA) deixa claro o interesse da junta militar de continuar com a realização da Copa do Mundo em 1978 em seu território, além de também gerar uma roupagem tecnocrática tanto para os clubes locais quanto, posteriormente, para a seleção nacional argentina que com o tempo as vitórias esportivas passaram a ser analisada com outros olhos (Magalhães, 2013).

A proximidade entre o ano do golpe militar (1976) e a realização do mundial (1978) não foi empecilho para o governo que, mesmo pressionado pela FIFA, não mediu esforços para prosseguir com os investimentos em estádios, aeroportos e estradas para o grande evento. É fato, também, que a desistência de sediar o evento seria negativo para a imagem do país. Entretanto foi em meio aos primeiros anos de golpe onde os militares decidiram de fato intervir no futebol nacional utilizando da seleção como identidade e representação da própria Argentina. Como afirma Magalhães (2013):

A organização - e aqui entram principalmente as obras realizadas - era a principal retorica no discurso do regime, que insistia em ideias como quando querem, os argentinos podem, ou mostramos ao mundo que somos capazes. (p. 95)

Dessa maneira, o discurso de superação nacional frente à crise política, social e econômica foi utilizado na realização do mundial em sua casa como oportunidade para mostrar as qualidades do povo argentino na superação dos problemas internos e das pressões externas atrelado ao simbolismo do futebol na questão identitária e cultural da própria nação. Foi na necessidade de legitimação interna diante da recente ruptura democrática (Arbena, 2007) que os militares utilizaram do torneio como artificio político perante a oportunidade de melhorar a imagem, não somente do Estado, para o exterior, mas também do governo, internamente.

Nesse sentido a realização da Copa na Argentina sofreu diversas pressões externas quanto ao boicote da realização do evento no país. Na França, em especial, foi criado o Comité d' Organization pour le Boycotte a la Coupe du Monde en Argentine (COBA) movimento ligado à esquerda no qual os manifestantes eram mobilizados pela questão da crise política atrelada aos conflitos violentos, censuras e principalmente pelos exilados argentinos (Magalhães, 2013). A organização denunciava a repressão que existia na Argentina à época, da mesma maneira que denunciavam o uso do aparato político do futebol como exemplo de violação dos Direitos Humanos diante da ONU e da Anistia Internacional.

Entretanto, mesmo diante das denúncias e do país na agenda internacional como símbolo de violência política, além da incerteza de seleções como Holanda e França que cogitavam o boicote, as medidas foram insuficientes diante de uma população argentina já há tempos apaixonada pelo futebol, unida pelo discurso da pátria que supera adversidades 
(Magalhães, 2013). A Copa do Mundo aconteceu na Argentina em 1978.

\section{b. BRASIL (1970) - A legitimação do tri}

Após 1958, ano do primeiro título de Copa do Mundo da seleção brasileira, o futebol no Brasil, através dos novos meios de comunicação e sua facilidade prática, tomou proporções maiores dentro de todo o país. Essa popularização fez com que o futebol alcançasse para além das zonas elitistas e atingisse setores mais humildes da sociedade. Alguns pesquisadores, como Agostino (2002) e Archetti (2013), apontam as características do atributo mobilizador do futebol como importantes para a utilização do esporte em práticas não somente de lazer, mas também como geradoras de interesse do Estado em sua prática (Guterman, 2006). Foi, portanto, através da capacidade do futebol em gerar uma identidade nacional que os governos, sendo eles democráticos ou regimes ditatoriais, passaram a utilizar da imagem da seleção brasileira como uma forma de aumentar sua popularidade e grau de legitimação (Magalhães, 2013).

A relação entre Estado e futebol no Brasil se estreitou ainda mais à época da ditatura militar brasileira. Foi durante a Copa do Mundo de 1970 que slogans ufanistas foram utilizados para gerar propaganda para o regime. Dentro desse aspecto a música do compositor Miguel Gustavo intitulada "Pra Frente Brasil", cantada durante toda a copa como incentivo aos atletas, virou símbolo do que realmente era ser brasileiro. Essa vinculação da imagem da seleção ao regime foi ainda maior após a conquista do tricampeonato mundial pelo Brasil. (Oliveira; Santos, 2014; Rodrigues, 2018).

Como afirma Fraga (2011):

A criação da imagem positiva de um governo através da associação a um atleta ou conjunto de atletas vencedores parece assumir um sentido ainda mais urgente nos momentos em que tais governos passam a carecer de legitimidade, seja diante de sua própria população, seja no plano externo (p.6)

A preparação para a Copa de 1970 - que ironicamente ocorreu no México, país destino para diversos exilados de esquerda brasileiros -, atuação da qual se tornaria um dos grandes feitos do período da ditadura, começou logo após a precoce eliminação brasileira na Copa da Inglaterra, em 1966. A fim de evitar uma crise no futebol nacional, a seleção, por pressão política, se moldava a militarização com foco na disciplina e na ordem (Magalhães, 2013).

É importante destacar que mesmo diante do período mais repressivo de toda a ditadura sofrida pelo Brasil no governo Médici, com diversas perseguições, sequestros de embaixadores e assassinatos, o futebol serviu como aparato de divulgação ideológica tanto pelas vias militares quanto pela pauta de grupos de esquerda. Na seleção brasileira se percebiam "conflitos e posições distintas que apareceram em diversos setores sociais de esquerda que tradicionalmente se opunham aos respectivos governos civil-militares" (Magalhães, 2013, p. 27).

As atuações geniais de Pelé, Jarzinho, Revelino e de todo o esquadrão coroavam o 
futebol brasileiro em cenário doméstico e mundial (Magalhães, 2011), de modo que se tornou uma estratégia de propaganda associar o presidente-torcedor ao futebol da seleção, "articulando os êxitos da seleção à imagem de Brasil-Potência que o governo procurava difundir" (Carvalho, 2011, p. 11-12).

A imagem da seleção brasileira após o tricampeonato mundial foi também atrelada a lógica desenvolvimentista do projeto militar - devido ao uso desse elemento como símbolo atrelado ao de um país no caminho certo do avanço - o "milagre econômico" que acontecia no país durante o governo do presidente Médici favoreceu o otimismo de alguns grupos sociais quanto a projeção do Brasil como potência internacional.

Nas palavras de Schatz (2012):

Os jogadores foram apresentados como brasileiros heróis que provaram a capacidade do país em projeção internacional e receberam elogios de líderes mundiais, como Richard Nixon, então Presidente dos Estados Unidos. (p. 11)

O governo de Médici se apoiou na vitória da seleção no mundial para ligá-lo diretamente aos avanços em termos econômicos, maquiar os problemas locais, além de propagar sua cultura e difundir seu "êxito nacional" perante seus críticos internos e externos (Guterman, 2006). Dessa maneira, a conquista do tricampeonato e o milagre econômico dariam projeção da imagem do país no cenário doméstico e internacional, ainda assim utilizando do futebol tanto como uma forma de alienação e manipulação da população aos problemas vividos no país quanto para promover o regime e favorecer a cultura e identidade brasileira para além das suas fronteiras (Couto, 2010).

\section{c) CHILE (1973) - A estrutura do lazer e da tortura no Estádio Nacional do Chile}

Assim como os vizinhos Argentina e Brasil, o Chile foi um dos pioneiros a difundir o futebol na região no início do século $X X$, sendo até hoje o esporte mais praticado e popular do país (Parra, 2016). Entretanto, é bem verdade que de início, mesmo com seus tradicionais estádios com construções colossais, os jogos, salvo os grandes clássicos, não atraiam grandes públicos (Brum, 2017). Aos poucos, com a participação da seleção na primeira Copa do Mundo em 1930 e as investidas chilenas em organizar torneios internacionais, o esporte se popularizava dentro de sua fronteira.

Essa disseminação do esporte está atrelada ao fator identitário que o futebol exerce na sociedade, como apontado anteriormente neste artigo. No caso chileno não foi diferente, visto que não somente os torcedores utilizaram da seleção chilena como símbolo do que seria de fato ser chileno, mas também serviu como um instrumento do próprio Estado, sendo ele antes ou depois do golpe militar sofrido em 1973 como símbolo nacionalista (Ortega et. al, 2004). É importante ressaltar no caso chileno, como aponta Parra (2016, p. 132), que os chilenos se orgulhavam de sua seleção, mesmo sem muitas conquistas relevantes futebolisticamente, como sendo a representação de um povo pobre, porém honrado, diferentemente do brasileiro e argentino onde suas seleções demonstravam-se como símbolos de exaltação de força (Magalhães, 2013). Essa vinculação da seleção junto ao povo chileno 
fica evidenciado ainda nas palavras de Parra (2016, p. 131), "la selección como una fuerza humilde a nivel internacional".

Anos antes do golpe militar, o Chile já demonstrava seu apreço pela prática futebolística e interesse na realização de eventos internacionais em seu território. O país foi palco da Copa do Mundo de 1962 - mesmo ameaçada de sua realização dois anos antes pelo terremoto ocorrido no país em 1960 - da qual foi conquistada pelos esforços incessantes do filho de um diplomata chileno, o presidente da Federação de Futebol do Chile, Carlos Dittborn Pinto (1921-1962) em uma intensa disputa pela realização do torneio com a Argentina (GloboEsporte, 2014). À exemplo da massificação causada pelo futebol nos torcedores chilenos, o Estádio Nacional do Chile recebeu o confronto entre Brasil e Chile no dia 13 de junho de 1962 pela semifinal da Copa do Mundo levando ao palco colossal chileno 76.594 pessoas para ver a vitória brasileira, que se sagraria bicampeã mundial naquele ano. Já na disputa pelo terceiro lugar o Chile conquistaria o que até hoje é seu melhor desempenho em copas, diante de quase 69 mil pessoas no mesmo estádio. Feito que foi celebrado dentro de um dos símbolos de orgulho do povo chileno e que posteriormente viraria palco para utilização e prisão de perseguições políticas e violência por parte do regime autoritário de Augusto Pinochet (1915-2006).

Em 1973 o país se encontrava imerso em uma grande crise econômica, política e humanitária, o que ocasionou na queda do socialista Salvador Allende provocada pelos militares no dia 11 de setembro do mesmo ano (Ortega et al. 2004). Nesse contexto, mesmo diante de um cenário de forte tensão da recém tomada de poder por parte dos militares, a seleção chilena ainda disputava uma vaga na Copa do Mundo de 1974, a ser realizada na Alemanha. A vaga seria decidida na repescagem, ironicamente em uma disputa entre a URSS e o Chile. A primeira partida do confronto ocorreu apenas 15 dias depois do golpe militar que instaurou um regime autoritário de direita e anticomunista no Chile. Em Moscou, a seleção chilena conseguiu segurar o placar em 0 a 0 , levando a disputa pela vaga nas eliminatórias para o Estádio Nacional do Chile, a qual deveria ser disputada dois meses depois.

Para melhor contextualização é importante analisarmos os primeiros meses do regime militar, marcado por diversos problemas logísticos para dar conta do elevado número de prisões, instrumento dos militares para combate aos simpatizantes de esquerda no país. Neste cenário as cadeias estavam cheias, de maneira que o governo precisou buscar soluções alternativas para suas prisões políticas (Brum, 2017). Nesse contexto, como aponta Brum (2017) foi inaugurado novos campos de concentração no deserto do Atacama e no Estádio Nacional.

Mesmo dentro do Estádio Nacional era impossível de mensurar o terror imposto pelo Estado em todo o Chile. Para abafar os tiros das sessões de fuzilamento, os soldados recebiam orientação de ligar os ventiladores dentro dos vestiários, mesmo em dias frios (Brum, 2017, p. 25)

Aproximadamente cerca de 40 mil pessoas foram presas no Estádio, além de haver uma estimativa de 400 mortes, mesmo que os números oficiais surgiram apenas 40 (Brum, 2017; Bullé, 2018). Esse cenário de violência e utilização do palco do jogo como campo de concentração para opositores ao governo foi, portanto, o principal motivo para a recusa do 
URSS em disputar o jogo da volta no Estádio Nacional. Conforme Parra (2016 p. 133) afirma, os dirigentes soviéticos argumentavam que jogar no estádio atentava contra "a prática esportiva em um país que reina o terror". Essa recusa da URSS serviu de intermédio para discursos nacionalistas e anticomunistas do regime ditatorial chileno. Ainda nas palavras de Parra (2016):

Ante la ofensiva soviética, los medios nacionales intensificaron su arremetida en el terreno de la moral. Según El Mercurio, Chile puede ser "un país pequeño, subdesarrollado, pero en materia de dignidad no nos vienen a dar lecciones, menos en el deporte". Agregaba que el nuevo gobierno honraría la tradición de un "país libre, cariñoso y cordial. En Chile se quiere al amigo cuando es forastero". De esta forma, ante un equipo que finalmente no disputó la revancha, según El Austral, el cuadro nacional alinearía con "la verdad" en el arco; la defensa sería resguardada con la "justicia", el "patriotismo", la "honradez" y la "austeridade. (p. 133)

Mesmo diante da recusa por parte da URSS - que até tentou argumentar que jogaria em qualquer outro estádio, alternativa que foi recusada pela FIFA - o apito inicial foi dado no dia 21 de novembro de 1973 no Estádio Nacional. Com o campo de jogo manchado de sangue humano e arrumado às pressas para a disputa, maquiando o verdadeiro terror que se acometia nos primeiros meses do regime, a seleção chilena se classificava para copa do ano seguinte diante de 25 mil torcedores chilenos que presenciaram o vergonhoso gol de Váldes diante uma meta sem goleiro (Brum, 2017; Mercatelli, 2017).

\section{Somente PROPAGANDA ouSOFT POWER ?}

As mudanças no cenário internacional ocorridas na segunda metade do século XX requisitaram novos conceitos e interpretações por parte da disciplina das Relações Internacionais. Era necessário compreender melhor os conflitos, mas também as relações de paz e de cooperação entre os países. Foi, então, no contexto pós Guerra Fria, onde se desencadearam pautas para conceitos e análises sobre as crescentes e novas relações e formas de poder para Estados, sendo um desses elementos o Soft Power (Hobsbawm, 1995).

O conceito de Soft Power cunhado por Joseph Nye é de fato bastante recente na literatura das RI. Entretanto, o próprio autor comenta que esse comportamento estava atrelado, implicitamente, em alguns eventos históricos antigos, onde é possível analisar a cultura como fator para conquistas mais brandas de alguns líderes (Nye, 2011). Nye (2011) indica ainda que o Soft Power é percebido também quando realistas clássicos tentam refutar a existência de um poder ameno, a exemplo de Edward Carr em 1939. Assim, Nye (2004; Apud MONTEIRO, 2015) define Soft Power como "a habilidade de influenciar os outros para realização de seus interesses através da atração e não da coerção" no qual pode ser angariado, como aponta Gueraldi (2005, p. 66), através "da cultura, dos ideais e das políticas adotadas por um país" abrem-se, então, possibilidades de se entender diversas fontes para adquirir o poder brando. Como fica ilustrado ainda nas palavras de Gueraldi (2005) sobre o caso brasileiro: 
Nos critérios de Nye, o Brasil é reconhecido internacionalmente por sua música (MPB e Bossa Nova) e qualidade de jogadores de futebol como Pelé, Romário, Ronaldo e Ronaldinho Gaúcho. (p. 76)

Joseph Nye, em sua obra intitulada "O futuro do poder" (2011), ainda aponta que a comunicação é outro fator estratégico importante quando analisado na forma de como o país pode cooptar e inserir-se no cenário internacional a fim de garantir seus interesses. Das quais podem ser usadas como campanhas políticas ou de propaganda. Deixa evidente também que eventos como a Copa do Mundo podem gerar imagem de promoção para esses países (Nye, 2011).

Ainda sobre a propaganda, esse elemento era fator importante para os regimes autoritários sul-americanos, principalmente diante de um cenário político com repressões, perseguições políticas e assassinatos, de maneira que se subjugava as manifestações coletivas (Cordeiro, 2014). Nesse quesito, é bem verdade que de fato os regimes militares, em especial Brasil e Argentina, em busca de legitimidade doméstica, utilizaram da propaganda atrelada ao futebol como símbolo da identidade e reflexo do crescimento nacional.

O caso argentino de 1978 é o mais emblemático para entender a tríade na relação entre futebol, política e identidade, a última inclusive mostrando-se, através da cultura, como um meio de controle interno e externo pelo governo, no qual o futebol ganhou força na mesma medida que gerava mais empatia e identificação além de respeito na comunidade internacional (Arbena, 1990).

É nesse cenário que a realização da Copa do Mundo de 1978 em seu território deixava o país ainda mais na pauta do debate internacional, tendo em vista as denúncias de violação aos direitos humanos e tentativas de boicote pelos exilados e aliados na França com o COBA, com o qual foi possível o uso pelos militares de discursos acusatórios para melhorar a imagem tanto interna quanto externamente. Cabe ressaltar que mesmo em meio à euforia vivida pelos argentinos com o título mundial, ainda que tenha sido conquistado no Estádio Monumental à 800 metros de um dos palcos de maior tortura por parte da ditadura militar ${ }^{9}$ (Boueri, 2014), houve reconhecimento positivo sobre a organização do evento pela mídia local e até brasileira - a qual exaltou além dos jogadores, também o governo militar como verdadeiros símbolos de prosperidade argentina. Entretanto essa notoriedade, com afirma Marczal (2016), trazida ao realizar o Mundial em casa, evidencia internacionalmente não só a promoção do regime, mas também os acontecimentos retratados internamente de violência e repressão.

Como aponta Marczal (2016):

Diante da amplitude global, massiva e midiática do evento, o governo não possuía condições de bloquear o debate público fomentado a partir do ce-

9 A ESMA (Escola Superior de Mecanica da Marinha) serviu como um centro de detenção clandestino para o período da ditatura militar entre 1976-1983 pelo qual estimasse ter passado quase 5000 mil prisioneiros políticos, posteriormente dados como desaparecidos (Leal, 2012). 
nário internacional. As denúncias sobre o terror e a opressão se disseminaram junto com a defesa do boicote. Apesar de não atingir o objetivo traçado, a campanha tornou notórios os crimes cometidos pelo Estado, bem como as tensões políticas que permeavam o país. (p. 456)

No caso do governo autoritário brasileiro, a conquista do terceiro título mundial permitiu à seleção brasileira trazer para casa de forma definitiva a taça Jules Rimet, o que ocasionou prestígio e reconhecimento internacional até mesmo para a moral da população. Slogans ufanistas como país do futebol, foram reproduzidos pelo ditador Médici tanto para gerar mais apreço pelo futebol da sociedade quanto para divulgação das recém-inauguradas Loterias Esportivas (Fino, Hintze, 2014). Esse vislumbre em utilizar do futebol como aparato político, econômico e cultural era mais uma das propriedades do esporte como um elemento de massificação e cultura popular do qual foi explorado pelo regime autoritário brasileiro. O símbolo de um país que dava certo foi amplamente difundido logo após a conquista.

Diferentemente da Argentina, que venceu a copa da ditadura em casa, o tricampeonato brasileiro foi conquistado em solo mexicano, o que propiciou mascarar os eventos violentos dos quais acometia no país, deixando apenas a euforia por parte dos brasileiros em ter a certeza de que o Brasil estava no caminho certo. $O$ que possibilitou ainda mais a vinculação da imagem de crescimento do país internacionalmente.

Já sobre o governo de Pinochet, a expectativa do confronto entre Chile e URSS estava atrelada para além de divulgar o que de fato era símbolo do povo chileno através de sua seleção nacional. Dentro da ótica nacionalista adotada pelo governo autoritário, os discursos oficiais continham elementos ideológicos para o distanciamento do viés esquerdista soviético angariado pelo governo anterior, de Salvador Allende, e contraste com o então apoio financeiro dos EUA para a implementação de um regime de direta no país. É importante ressaltar, portanto, que a consequência desse discurso anti-esquerdista foi a suspensão das relações entre Chile e União Soviética (Ávila, 2014), refletido no cancelamento da partida, substituído por uma vexatória vitória no Estádio Nacional.

De fato, a propaganda - um dos instrumentos dos quais o Soft Power, segundo Nye, pode se desenvolver - através do futebol foi um dos elementos utilizados para gerar legitimidade interna para os regimes autoritários sul-americanos, sabendo também que é através desse esporte, como aponta Amazarray (2011, p. 63), onde "se propagam ideias, definem regimes, se organizam resistências e se emularam conflitos". Contudo analisando a política externa dos países nessa seção e os casos envolvidos no cenário do futebol internacional na seção anterior é possível identificar um Soft Power prematuro, através do futebol, para os países do Cone Sul?

É preciso analisar os casos separadamente quando observado dessa ótica, já que os países estudados mesmo com situações políticas semelhantes tiveram casos de repercussão internacional diferente uns dos outros.

Nesse cenário se observa a tentativa frustrada da Argentina em angariar prestígio e legitimação internacional, mesmo que seus feitos em infraestrutura tenham sido ressalta- 
dos por parte do país vizinho Brasil e a euforia quase religiosa tenha tomado conta da população argentina decorrente da primeira conquista de título mundial (Amazarray, 2011). Após a agenda internacional evidenciar o país sobre as graves violações dos direitos humanos, o país se viu investigado, o que ocasionou pressão para a Junta Militar da qual recebeu posteriormente a visita da Comissão Interamericana de Diretos Humanos (Boueri, 2014).

Observa-se no caso brasileiro, entretanto, efeitos diferentes. A conquista do tricampeonato deixou o país em um ambiente futebolisticamente importante para o desenvolvimento do termo país do futebol (Guterman, 2006). O prestigio internacional ajudava a difundir a identidade brasileira para além do âmbito interno até um patamar de seleção mágica internacionalmente através de personagens como Pelé e, mesmo sem entrar em campo, de João Havelange (1916-2016) - então presidente da Confederação Brasileira de Desportos (equivalente à CBF da época) que utilizou o tricampeonato brasileiro em sua campanha para presidência da FIFA, vencida em 1974 (Magalhães, 2013). Pode-se dizer, assim, que essa conquista brasileira o elevou no cenário do futebol internacional, ocasionando posteriormente indicações do próprio Nye (2012) sobre o Brasil possuir características importantes para aplicação do Soft Power nos dias atuais, sendo o país símbolo da "cultura do carnaval e do futebol".

O Chile, por sua vez, é o país mais difuso dentre os estudados. Tendo em vista a popularidade do futebol no país antes mesmo do golpe em 1973 e do fator identitário peculiar exercido pelo futebol. Cabe ressaltar que no caso chileno o futebol e a seleção simbolicamente representam seu povo humilde, e não grandiosos esquadrões e nações. Nessa conjectura os militares viram a possibilidade de utilização do jogo das eliminatórias da copa em 1973, a ser disputado contra a URSS, como parâmetro de um discurso militar para perpetuar ideias direitistas no país recentemente tomado por um regime autoritário rigorosamente violento e anti-comunista. Dessa maneira, o futebol exerceu claramente um papel interno de perpetuação dos ideais e dos valores do governo autoritário10, utilizando-se da URSS como ilustração do que o povo chileno seria agora capaz de vencer.

Analisando o conceito de Soft Power no que diz respeito às relações de poder por parte dos atores internacionais, Nye (2011, p. 118) afirma que "o poder brando depende de credibilidade, e quando os governos são percebidos como manipuladores e a informação é visto como propaganda, a credibilidade é destruída". Nisso, podemos diferenciar a propaganda, evidente nos três casos analisados, e que pode ser bem ou mal sucedida; e o soft power, que apenas se refere a inserção mundial bem sucedida.

Observando os casos e tomando o cuidado que Joseph Nye pede ao analisar as fontes e formas de conquistar o poder brando, não identificamos que os casos de Argentina e Chile tenham resultado em soft power. Essas tentativas nacionalistas de vincular a seleção de futebol com os governos autoritários tiveram impactos limitado na promoção da ordem e da

100 jogo exemplifica alguns desses valores do governo Pinochet: tortura, ao ser realizado no Estádio Nacional, onde o regime torturava e matava opositores políticos; e covardia, ao ter sido "vencido" por WO na ausência do comparecimento da seleção soviética. 
disciplina internamente, bem como chamaram a atenção para os crimes aos Direitos Humanos cometidos por esses países, como ficou evidente no caso Argentino.

O exemplo brasileiro, por outro lado, demonstra o uso bem sucedido do soft power, uma vez que a conquista da Copa do Mundo de 1970 projetou o Brasil ao ápice da glória internacional do esporte. Além do título, a performance da seleção brasileira naquele ano compõe o imaginário cultural desse país. Aproveitando a boa performance econômica daqueles anos, o governo foi bem sucedido em se aliar à seleção nacional, impactando em prestígio interno. Internacionalmente, tornou-se para sempre o país do futebol.

\section{5. considerações finais}

Os países do Cone Sul da América Latina se viram imersos, a partir de 1964, em um novo tipo característico de ditadura militar, concentrado em doutrinas de segurança nacional dos quais adquiririam um caráter tecnocrático para o Estado agora militarizado.Essa militarização do Estado está presente nas características dos Estados Burocráticos-Autoritários, onde os militares assumiam o papel de governantes políticos em setores importantes dentro do governo. Os militares também eram agentes da repressão e detinha a função do combate aos movimentos de forças populares - através de ações violentas, de perseguição, assassinatos, prisões, exílios e torturas - além de contenção as instituições democráticas.

No cenário da Guerra Fria onde esses Estados burocráticos-autoritários surgiram, novas perspectivas para a análise das relações internacionais foram possíveis a partir de novos níveis de interdependência e globalização que favoreceram a criação de elementos inovadores para suas possíveis aspirações e legitimações tanto no âmbito interno e externo dos países.Um dos instrumentos para alcançar essas aspirações é o esporte - elemento, inclusive, que fora utilizado antes mesmo da Guerra Fria para propaganda de regimes - analisado com novos olhos pelos atores pela capacidade de vitrine que um evento internacional pode resultar (Vasconcellos, 2008). Dentro da região sul-americana o apreço por um esporte específico, o futebol, fez com as ditaduras militares utilizassem do mesmo para angariar interesses em promoção de seus regimes.

Como demostrado durante os casos envolvendo esses Estados, fica evidenciado o papel de massificação desempenhado pelo futebol dentro da sociedade argentina, brasileira e chilena por uma série de fatores identificados durante o trabalho. A questão da identidade nacional atrelada ao futebol foi um dos aspectos motores que fizeram os militares utilizarem do futebol em benefício de seus governos tanto em legitimação interna quanto para fins de propaganda internacional.

O artigo almejou deixar claro o caráter importante que o futebol teve na promoção dos regimes autoritários de Argentina, Brasil e Chile. As conquistas do tricampeonato mundial da seleção brasileira 1970, deixou o país em um patamar de prestígio internacional e ajudou a difundir o que hoje compreendemos como o país do futebol, o que nos permite identificar esse caso como sendo soft power. A Copa na Argentina deu roupagem para mostrar que o país poderia realizar um evento de grande porte mesmo em meio as tensões internacionais sofridas pelo país, entretanto, mesmo diante da transformação da Copa na Argentina para a Copa da Argentina trouxe consigo também novas apreensões e denúncias 
internacionais para os acontecidos vigentes no país. O Chile, por sua vez, fez da desistência da URSS uma arma ideológica para promoção de suas intenções de direita, além de mascarar o seu maior palco futebolístico das violências cometidas dentro do Estádio Nacional com um jogo no qual se tornou um dos capítulos mais vergonhosos de sua seleção.

Toda a prática esportiva adquiriu com o passar dos anos um grande número de adeptos e admiradores. Alguns historiadores apontam o esporte como um dos fenômenos culturais mais importantes do século XX (Houlihan, 1994: 52). Nesse sentido, com o futebol não foi diferente, fomentado pela sua facilidade pratica e seu caráter identitário fez com o esporte se popularizasse em todo o mundo. É com esse olhar crítico que podemos identificar a importância do presente estudo para a disciplina de Relações Internacionais baseado na clara utilização do futebol como ato político tanto em regimes autoritários quanto em democracias para promoção de seus governos perante sua própria sociedade e em demonstrações internacionais simbolizantes da sua nação.

\section{Referências}

Agostino, Gilberto (2002). Vencer ou Morrer: Futebol, Geopolítica e Identidade Nacional. Rio de Janeiro: Editora Mauad.

Amazarray, Igor Chagas (2011). Futebol: O esporte como ferramenta política, seu papel diplomático e o prestígio internacional. Trabalho de conclusão de curso. Disponível em: <https://www.lume.ufrgs.br/handle/10183/40288>. Acesso em: 04/06/2019.

Arbena, J. L (1990). "Generals andgoles: assessing the connection between the military and soccer in Argentina". The International Journal of the History of Sport, 7 (1), p. 120-130.

Archetti, Eduardo P (2008). "El potrero y el pibe: territorio y pertenencia en el imaginario del fútbol argentino". Horizonte antropolólico, vol.14, n.30, p.259-282.

Arendt, Hannah (1979). As Origens do Totalitarismo. São Paulo: Companhia das Letras.

Ávila, Carlos Federico Domínguez (2012). “O golpe no Chile e a política internacional (1973): ensaio de interpretação”. 2012. Disponível em: <http://www.scielo.br/pdf/his/v33n1/14.pdf> Acesso em: 20/09/2019.

Barbosa, Wilton Dias; Portilho, Isaque Elias (2016). “As Políticas Externas de Argentina e Brasil Durante seus Regimes Militares: Uma abordagem comparativa.". Relações Internacionais, n. 51, p. 107-123.

Barros, Cesar Mangolin (2011). “A ditadura militar no Brasil: processo, sentido e desdobramentos". Disponível em: <https://cesarmangolin.files.wordpress.com/2010/02/cesar-mangolin-de-barros-a-ditadura-militar-nobrasil-2011.pdf> Acesso em: 15/10/2019.

Borges, Adriana Cristina; Cabello, Norder Luiz Antônio (2008)."Tortura e Violência Por Motivos Políticos no Regime Militar no Brasil." Disponível em: 
<http://www.uel.br/eventos/sepech/sepech08/arqtxt/resumos-anais/AdrianaCBorges.pdf> Acesso em 02/10/2019.

Boueri, Aline Gatto. (2014) "Copa do Mundo de 1978 ajudou a divulgar crimes da ditadura da Argentina". OperaMundi, 11 de junho de 2014. Disponível em: <https://operamundi.uol.com.br/politica-e-economia/35624/copa-do-mundo-de-1978-ajudou-a-divulgar-crimes-da-ditadura-da-argentina> Acesso em: 14/11/2019.

Brum, Mauricio (2017). La cancha infame: a história da prisão política no Estádio Nacional do Chile. Porto Alegre: Zouk. 2017.

Bullé, Jamille (2018). "Há 45 anos, Estádio Nacional do Chile foi palco de prisões e tortura da ditadura chilena.". Globoesporte, 2018. Disponível em: <https://globoesporte.globo.com/futebol/futebol-internacional/noticia/ha-45-anos-estadionacional-do-chile-foi-palco-de-prisoes-e-tortura-da-ditadura-chilena.ghtml>. Acesso em: 07/11/2019

Candeas, Alessandro Warley (2005). "Relações Brasil-Argentina: uma análise dos avanços e recuos." Revista Brasileirade Política Internacional, 48 (1), p. 178-213.

Canettieri, Thiago (2010). "A Importância do Futebol Como Instrumento da Geopolítica Internacional." Revista de Geopolítica, v. 1 n² 2 p. 116-135.

Carvalho, Beatriz Thomaz (2011). "Futebol e política externa: um olhar sobre as relações Brasil-Argentina." 3o Encontro Nacional da ABRI. Belo Horizonte, 2011. Disponível em: <http://www.abri.org.br/anais/3_Encontro_Nacional_ABRI/Politica_Externa/PE\%208_Beatriz\%20Thomaz\%20Carvalho\%20FUTEBOL\%20E\%20POL+\%ECTICA\%20EXTERNA\%20UM\%20OLHAR\%20SOBRE\%20AS\%20RELA+\%E7+\%F2ES\%20BRASIL-ARGENTI.pdf>. Acesso em: $30 / 10 / 2019$

Catela, Ludmila da Silva (1998). "Argentina: do Autoritarismo à democracia, da repressão ao mal-estar castrense 1976-1989". Texto Cpdoc n²8. FGV.

Cifuentes, Pedro (2015). “A memória do horror, no Estádio Nacional do Chile”. El País, 11 de junho de 2015.Disponível em: <https://brasil.elpais.com/brasil/2015/06/11/deportes/1433979308_782555.html>. Acesso em: 30/10/2019.

Couto, Euclides de Freitas (2010). "A esquerda contra-ataca: rebeldia e contestação política no futebol brasileiro (1970-1978)". Revista de História do Esporte v. 3, n 1. Disponível em: <https://revistas.ufrj.br/index.php/Recorde/article/view/744/685>. Acesso em: 14/10/2019

Departament Of State (2014). Foreign Relations of the United States. 2014. Disponivel em: <https://static.history.state.gov/frus/frus1969-76v21/pdf/frus196976v21.pdf> Acesso em: 30/10/2019.

Dias, Gustavo Monteiro (2015). "Política e Futebol: A Copa do Mundo de 1978 na Argentina". Trabalho de Conclusão de Curso" Disponível em: <http://bdm.unb.br/bitstream/10483/12362/1/2015_GustavoMonteiroDias.pdf> Acesso em: 19/10/2019. 
GloboEsporte (2014). "Ditadura militar: a protagonista da Copa de 78 na Argentina”. O Globo. Disponível em: <https://oglobo.globo.com/mundo/ditadura-militar-protagonista-da-copa-de-78-na-argentina-8425995>. Acesso em: 02/11/2019

Fino, Patricia; Hintze, Hélio (2017). “Jogada de Médici: o uso da loteria esportiva pelo regime militar brasileiro." Laboratório de Estudos Urbanos. Disponível em: <https://www.labeurb.unicamp.br/rua/web/index.php?r=paginasartigo/viewpagina\&numeroPagina=1\&artigo_id=95>. Acesso: em: 28/10/2019.

Fraga, Gerson Wasen (2011). "Futebol, imprensa e ditadura: das formiguinhas de geisel à abertura de telê". Anais do XXVI Simpósio Nacional de História, São Paulo, 2011. Disponível em: <http://www.snh2011.anpuh.org/resources/anais/14/1300985039_ARQUIVO_DasformiguinhasdeGeisel.pdf>. Acesso em: $24 / 10 / 2019$.

Frydenberg, Julio (1999). Redefinición del fútbol aficionado y del fútbol oficial. Buenos Aires: Deporte y Sociedad.

Garcia, Fernanda Machado (2015). "Esporte como instrumento de soft power: o futebol brasileiro." Trabalho de Conclusão de Curso Disponível em: <https://repositorio.ufsc.br/xmlui/bitstream/handle/123456789/158275/Monografia\%20da\%20Fernanda\%20Garcia.pdf?sequence=1\&isAllowed=y $>$. Acesso em: 03/05/2019.

Giulianotti, Richard (2010). Sociologia do Futebol - Dimensões Históricas e Socioculturais do esporte das multidões. São Paulo: Nova Alexandria.

Gueraldi, Ronaldo Guimarães (2005). A Aplicação do conceito de poder brando (Soft Power) na política externa brasileira.Dissertação de Mestrado. Disponível em: $<$ http://bibliotecadigital.fgv.br/dspace/bitstream/handle/10438/3552/ACFC3.pdf?sequence=1>. Acesso em: 13/11/2019.

Guterman, Marcos (2006). O Futebol Explica o Brasil: o Caso da Copa de 70. E-book. Disponível em: <http://livros01.livrosgratis.com.br/cp007788.pdf>. Acesso em: 24/10/2019

Hobsbawn, Eric (1995). Era dos Extremos. O breve século XX 1914-1991. São Paulo: Companhia das Letras.

Houlihan, Barrie (1994). Sport and International Politics. Hemel Hempstead: Harvester Wheatsheaf.

Junior, Jorge Nelson Cáceres Olave (2015). “A Ditadura Militar no Brasil e no Chile: Um Estudo Comparativo da Participação dos Militares e Civis na Trama Golpista.". 3a Semana de Ciência Política da UFSCAR, 2015. Disponível em: <http://www.semacip.ufscar.br/wp-content/uploads/2014/12/Jorge-Nelson-C\%C3\%A1ceresOlave-J\%C3\%BAnior.pdf> Acesso em 24/09/2019.

Junior, José C.M. B.; Livacic, G. E. P. (2017). “Estados Autoritários no América Latina: uma revisão crítica ao conceito de Estado Burocrático-Autoritário em Guillermo 
O'Donnell.".REBELA, v.7, n.2. Disponível em: <https://rebela.emnuvens.com.br/pc/article/view/346> Acesso em: 23/08/2019.

Leal, Bruno (2012). "A “Escola do Terror" na ditadura argentina.". Café História. 02 de fevereiro de 2012. Disponível em: < https://www.cafehistoria.com.br/a-escola-doterror-na-ditadura-argentina/> Acesso em: 23/10/2019.

Llonto, Pablo (2005). La Verguenza de todos: el dedo em la llaga del Mundial de 78. Buenos Aires: Asoc Madres del Plaza de Mayo.

Magalhães, Lívia Gonçalves (2011). Futebol em tempos de ditadura civil-militar.Anais do XXVI Simpósio Nacional de História, São Paulo, 2011. Disponível em: <http://www.snh2011.anpuh.org/resources/anais/14/1300850798_ARQUIVO_MagalhaesLiviaANPUH2011.pdf>. Acesso em: 02/10/2019

Magalhães, Lívia Gonçalves (2013). "Com a taça nas mãos: sociedade, copa do mundo e ditatura no Brasil e Argentina."Tese de Doutorado. Disponível em: $<$ https://www.historia.uff.br/stricto/teses/Tese-2013_LiVIA_GONCALVES_MAGALHAES.pdf>. Acesso em: 02/10/2019

Magalhães, Lívia Gonçalves; Cordeiro, Janaina Martins (2016). “O poder na torcida: consenso, futebol e ditadura no brasil (1970) e na argentina (1978)." Revista Discente da Pós-Graduação em História, v. 2, n. 4. Disponível em: <http://www.ufjf.br/facesdeclio/files/2014/09/4.Artigo-D1.-Jana\%C3\%ADna.pdf>. Acesso em: $24 / 10 / 2019$

Marczal, Ernesto Sobocinski (2016). ¿Qué otra cosa se puede festejar? Paixão e política nas narrativas sobre a copa do mundo de futebol na argentina (1975-1978). Tese de Doutorado. Disponível em: <https://acervodigital.ufpr.br/bitstream/handle/1884/44987/R\%20-\%20T\%20-. \%20ERNESTO\%20SOBOCINSKI\%20MARCZAL.pdf?sequence=1\&isAllowed=y $>$. Acesso em: $27 / 10 / 2019$

Monteiro, Tiago Francisco (2012). "Análise dos projetos políticos "transicionais" dos militares da Argentina, Brasil e Chile em perspectiva comparada". 360 Encontro Anual da ANPOCS. Disponível em: <https://anpocs.com/index.php/encontros/papers/36-encontro-anual-da-anpocs/gt-2/gt14-2/8003-analise-dos-projetospoliticos-transicionais-dos-militares-da-argentina-brasil-e-chile-em-perspectiva-comparada/file> Acesso em: 07/10/2019.

Neto, Tomaz Espósito (2006). "A diplomacia das Armas: Considerações sobre a política externa argentina do período militar (de 1976 a 1983)."Ensaio. Disponível em: $<$ https://pt.scribd.com/document/131725200/esposito-tomaz-a-diplomaciadas-armas-consideracoes-sobre-a-politica-externa-argentina-do-periodo-militar>. Acesso em: 06/10/2019.

Nye, Joseph S (2012). O futuro do poder. São Paulo. Editora: Benvirá.

Nye, Joseph S. (1990) "Soft Power". Foreign Policy. n. 80, p. 153-171.

O’Donnell, Guillermo (1990). Análise do Autoritário Burocrático. São Paulo: Paz e Terra. 
O’Donnell, Guillermo (2011). Autoritarismo y Modernización. Buenos Aires: Prometeo.

O’Donnell, Guillermo (1972). Modernization and Bureaucratic-Authoritarianism. Berkeley: Institute of International Studies.

Oliveira, Eduardo Neves Faria de (2015). As Relações Internacionais e o futebol como diplomacia de paz. Trabalho de Conclusão de Curso. Disponível em: $<$ bdm.unb.br/bitstream/10483/11372/1/2015_EduardoNevesFariadeOliveira.pdf>. Acesso em: 07/06/2019.

Oliveira, Rodrigo S.; Dos Santos, J. G. V (2014). Ditadura e Copa do Mundo de 1970 nas páginas da Folha de Londrina. XIV Encontro Nacional de História. Disponivel em: <http://www.erh2014.pr.anpuh.org/anais/2014/237.pdf>. Acesso em: $28 / 10 / 2019$

Ortega, Eugenio R; Güell P.; Lechner, N.; Márquez, R. A; Soledad, G. M (2004). Desarrollo humano em Chile: nosotros los chilenos: un desafio cultural. LOM Ediciones. 2004.

Paniago, Flavia Cristina (2016). “A instauração da ditadura militar no Chile: os documentos do Centro de Informações Exteriores - CIEX (1970 - 1973) e o posicionamento brasileiro."Trabalho de Conclusão de Curso. Disponível em: <http://bdm.unb.br/bitstream/10483/19206/1/2016_FlaviaCristinaPaniago.pdf> Acesso em 23/09/2019.

Parra, Diego Vilches (2016). "Del Chile de los triunfos morales al "Chile, país ganador". La identidad nacional y la selección chilena de fútbol durante la Dictadura Militar (1973-1989)". Historia Critica, n. 61. Disponível em: <https://revistas.uniandes.edu.co/doi/pdf/10.7440/histcrit61.2016.07>. Acesso em: 07/11/2019.

Ricupero, Bernardo (2015). "Da Estrutura à Agência: Momentos Da Interpretação de Guillermo O’Donnell Sobre o Autoritarismo Latinoamericano." Crítica e Sociedade: revista de cultura política. v. 4, n. 2. Disponível em: < http://www.seer.ufu.br/index.php/criticasociedade/article/view/26116> Acesso em: 10/09/2019.

Roldán, Diego P (2007). "La espontaneidad regulada. Fútbol, autoritarismo y nación en Argentina '78. Una mirada desde los márgenes". Prohistoria, n. 11, p. 125-147.

Schatz, Patricia Volk (2012). “O Brasil em campo: relações entre futebol, política e economia através da análise do jornal folha de São Paulo (1964-1970)". CaderNAU, v.6, n.1. Disponível em: <https://periodicos.furg.br/cnau/article/view/4764>. Acesso: 24/10/2019

Vasconcellos, Douglas Wanderley de (2008). Esporte, poder e relações internacionais.Brasília: Fundação Alexandre de Gusmão. 